\title{
Post-irradiation somatic mutation and clonal stabilisation time in the human colon
}

\author{
F Campbell, G T Williams, M A C Appleton, M F Dixon, M Harris, E D Williams
}

\begin{abstract}
Background-Colorectal crypts are clonal units in which somatic mutation of marker genes in stem cells leads to crypt restricted phenotypic conversion initially involving part of the crypt, later the whole crypt. Studies in mice show that the time taken for the great majority of mutated crypts to be completely converted, the clonal stabilisation time, is four weeks in the colon and 21 weeks in the ileum. Differences in the clonal stabilisation time between tissues and species are thought to reflect differences in stem cell organisation and crypt kinetics.
\end{abstract}

Aim-To study the clonal stabilisation time in the human colorectum.

Methods-Stem cell mutation can lead to crypt restricted loss of $\mathrm{O}$-acetylation of sialomucins in subjects heterozygous for O-acetyltransferase gene activity. mPAS histochemistry was used to visualise and quantify crypts partially or wholly involved by the mutant phenotype in 21 informative cases who had undergone colectomy up to 34 years after radiotherapy.

Results-Radiotherapy was followed by a considerable increase in the discordant crypt frequency that remained significantly increased for many years. The proportion of discordant crypts showing partial involvement was initially high but fell to normal levels about 12 months after irradiation.

Conclusions-Crypts wholly involved by a mutant phenotype are stable and persistent while partially involved crypts are transient. The clonal stabilisation time is approximately one year in the human colon compared with four weeks in the mouse. The most likely reason for this is a difference in the number of stem cells in a crypt stem cell niche, although differences in stem cell cycle time and crypt fission may also contribute. These findings are of relevance to colorectal gene therapy and carcinogenesis in stem cell systems.

(Gut 1996; 39: 569-573)

Keywords: colon, clonality, stem cell, mutation, radiation, cell kinetics.

The intestinal epithelium is a stem cell tissue, which is organised into structurally coherent clonal units with each unit maintained by one or more stem cells; the clonal units have been identified morphologically as the crypts of Lieberkühn. ${ }^{12}$ The hierarchy of cells involved in the maintenance of clonal units has been investigated using markers such as tritiated thymidine or bromodeoxyuridine but the fact that the nuclear activity is diluted with each successive division following a pulse label and that the great majority of S-phase cells that take up the label are not stem cells make it difficult to determine accurately the organisation and kinetics of stem cells, particularly as these cannot be identified separately. ${ }^{3}$

Phenotypic changes caused by mutation are capable of giving rise to a permanent change in the clonal unit if the mutation occurs in a stem cell. We have previously shown that mutagen induced loss of glucose-6-phosphate dehydrogenase (G6PD) activity visualised by histochemistry can be used to demonstrate such a clonal phenotypic change in widely scattered crypts in the mouse colon. ${ }^{1}$ Time course studies allowed the evolution of crypt colonisation by the mutant phenotype to be followed. ${ }^{45}$ Five days after a single administration of mutagen most of the discordant crypts were partially involved by cells expressing low levels of the G6PD mutated phenotype. The frequency of these diminished over the four weeks after mutagen administration as the number of discordant crypts in which the whole clonal unit was occupied by mutant cells increased. The frequency of wholly discordant crypts reached stability at about the same time as the frequency of partially involved crypts fell to very low levels. Similar findings have been made in the mouse small intestine either using G6PD ${ }^{5}$ or a technique that detects mutations in mice heterozygous for a gene controlling lectin binding, ${ }^{2}{ }^{6}$ but here the time taken to reach the plateau in the frequency of wholly discordant crypts was up to five times longer than in the colon. We consider it likely that this surprising difference between small and large intestines is due to tissue variation in the number and organisation of stem cells located within a crypt stem cell niche, ${ }^{2}$ although differences in stem cell kinetics or crypt fission would also contribute. ${ }^{57}$ Whether this or other models of crypt organisation are used, the time taken to reach the plateau represents the time taken for the progeny of one stem cell to populate the whole clonal unit in nearly all mutated crypts. ${ }^{4}$ This may be termed the clonal stabilisation time.

We have also demonstrated a monogenically inherited polymorphism for the histochemical staining of human colorectal mucosa by a technique (mPAS) that discriminates 
O-acetylated (mPAS negative) from nonO-acetylated (mPAS positive) epithelial sialomucoproteins. ${ }^{8}$ Somatic mutation of the high acetylator allele in crypt stem cells in heterozygous subjects followed by crypt colonisation by the mutant progeny leads to conversion of the crypt phenotype from mPAS negative to mPAS positive and we have used this to identify and quantify somatic mutations in colectomy specimens. ${ }^{910}$ Radiation given one month before colectomy for carcinoma led to a considerable increase in frequency of mPAS positive discordant crypts, but the increase was very largely confined to crypts showing partial involvement by the mutant phenotype, ${ }^{10}$ and no information is available on the clonal stabilisation time in human colon. Unlike G6PD histochemistry, the mPAS technique can be used on archival formalin fixed tissues. We have therefore used mPAS staining to study mutation in colectomy specimens from patients who had radiation to the pelvic area at varying times up to 34 years before colectomy. The results suggest that the time taken for the progeny of one stem cell to replace all the cells of a colonic crypt in humans is approximately 12 months.

\section{Methods}

Colectomy specimens were available for study from 38 patients who had received prior therapeutic radiation. The age of the patients at radiation ranged from 31 to 77 years, the age at operation from 33 to 79 years, and the elapsed time between radiation and colectomy from four months to 34 years. There were 31 women. The radiation was given as treatment for carcinoma of the cervix (18 cases), bladder (4 cases), anorectum (3 cases), endometrium ( 2 cases), prostate (2 cases) or other tumours (9 cases). Colonic resection was undertaken for colorectal carcinoma in three cases, a sigmoid colon adenoma in one, symptoms attributed to radiation proctocolitis in 33 cases, and for obstruction in one. The radiation dose given ranged widely, from $4000 \mathrm{cGy}$ of fractionated external beam radiation in a patient with carcinoma of the rectum to a combination of 4000 cGy of fractionated external beam radiation and $4800 \mathrm{cGy}$ of intracavitary radiation to a patient with carcinoma of the cervix. The relationship of the part of colon sampled to the field irradiated could not be determined accurately, particularly in the cases where intracavitary radiation was given, as the tissue dose falls rapidly with distance from the source.

One hundred and twenty consecutive large bowel resection specimens for sporadic primary colorectal cancer $^{8}$ were used for comparison. The patients were aged 28 to 94 years at the time of surgery and there were 57 women. None of these patients had received pre-operative radiotherapy or cancer chemotherapy.

The tissues studied consisted of formalin fixed paraffin wax embedded blocks of resection margins taken during routine histological examination for diagnostic pur- poses. In non-irradiated colons these were invariably normal macroscopically and microscopically whereas some blocks from irradiated colons showed minor histological changes of radiation colitis. However blocks showing active inflammation, ulceration or severe distortion of the mucosal architecture were excluded. One $5 \mu \mathrm{m}$ section from each case was stained with the mPAS technique ${ }^{11}$ to discover if the phenotype was homozygous for low O-acetyl transferase activity (showing mPAS positive staining of all crypts). All other cases were largely or completely negative on staining with mPAS and further multiple mPAS stained step sections from blocks of each of these cases were obtained such that at least 10000 crypt profiles (the minimum required for confident assessment of mutated crypt frequencies $^{12}$ ) were examined for each subject. ${ }^{8} 10$ These step sections were cut at $80 \mu \mathrm{m}$ intervals to obtain the necessary size of sample while keeping the chances of counting the same crypt (normal or mutated) in adjacent sections at a low level. The total sample of crypt profiles examined in each case was determined by counting manually all of the profiles in one central step section (using a hand held tally) and multiplying this figure by the number of step sections examined (usually 10-20 per case).

In all cases with mPAS positive crypts in an mPAS negative background the number of discordant crypts was counted, and each recorded as partially or wholly replaced by the mutant phenotype. Results were expressed as the frequency of either wholly involved or partially involved crypts $\times 10^{-4}$. Statistical comparisons between patient groups were made using the Mann-Whitney U test.

\section{Results}

Thirty eight cases where colectomy had been performed four months or more after completing a course of abdominal radiotherapy were available for study. Thirty were unselected cases, of which four showed uniformly low levels of O-acetylation (mPAS positive), nine were excluded because less than 10000 crypts were available for study, and four showed uniformly high levels of $\mathrm{O}$-acetylation (mPAS negative). This left 13 cases with the heterozygous phenotype, showing high levels of O-acetylation and scattered crypts in which the mPAS negative phenotype was completely or partially replaced by cells that had lost O-acetylation (mPAS negative with scattered positive crypts). These cases were suitable for quantitation of somatic mutation frequency. A further eight irradiated cases with discordant mPAS positive crypts in an mPAS negative background were derived from other studies, giving a total of 21 informative cases.

The 120 specimens with sporadic colorectal cancer untreated by radiation or chemotherapy included 15 uniformly mPAS positive, 52 uniformly mPAS negative, and 53 predominantly mPAS negative with scattered mPAS positive crypts. More than 10000 crypts were available for assessment in all of these cases. 
The frequency of wholly involved discordant crypts in the 21 informative irradiated cases was very variable, ranging from $4.3 \times 10^{-4}$ to $128.3 \times 10^{-4}$, as were the frequencies of partially involved crypts which ranged from 0 to $39 \cdot 1 \times 10^{-4}$. The overall mean (SD) and median for all 21 informative cases was 37.7 $(35.1) \times 10^{-4}$ (median $26.3 \times 10^{-4}$ ) for wholly affected crypts, $7 \cdot 8(10.4) \times 10^{-4}$ (median $3.4 \times 10^{-4}$ ) for partially involved crypts, and $45.5(39.8) \times 10^{-4}$ (median $33.8 \times 10^{-4}$ ) for all affected crypts. These figures compare with $10.9(11.7) \times 10^{-4}$ (median $7.5 \times 10^{-4}$ ) for wholly affected crypts, $1.0 \quad(1.0) \times 10^{-4}$ (median $0.9 \times 10^{-4}$ ) for partially affected crypts, and $11.8(12.1) \times 10^{-4}$ (median $7 \cdot 7 \times 10^{-4}$ ) for all affected crypts from the 53 informative control colorectal cancer specimens that had not received prior radiation. The frequencies of wholly involved, partially involved and all discordant crypts show a statistically significant increase in the irradiated compared with the non-irradiated patients (Mann-Whitney U, $\mathrm{p}<0.0001$ for each comparison).

To evaluate the results in relation to the time period after radiation, the 21 irradiated cases were divided into three groups of approximately equal size, 4-12, 13-24, and $>25$ months after radiotherapy. Although the tissue radiation dose could not be determined accurately the range of radiation given was approximately the same in each of the groups. The results are presented in the Table, along with those from the non-irradiated cases and a previously published study of seven similarly aged informative subjects given $4000 \mathrm{cGy}$ of fractionated external radiation one month before operation for colorectal cancer. ${ }^{10}$ Because the data were not normally distributed, the results are shown as medians and ranges. The frequency of wholly discordant crypts rises significantly $(p<0.003$ ) 4-12 months after radiation, and remains raised thereafter without changing significantly. The frequency of partially involved crypts is also significantly increased 4-12 months after radiation $(p<0.002)$ and then falls with time. However, it does not return to the low frequency seen in non-irradiated cases, the median value of $2 \cdot 1 \times 10^{-4}$ at $>25$ months being significantly higher $(p<0.01)$ than $0.9 \times 10^{-4}$ observed in the non-irradiated group.

A wide variation in the frequencies of discordant crypts between cases in each of the three groups of irradiated cases studied would be expected because it was not possible to determine the spatial relation between the exact part of the colon available for study and the radiation field. We have therefore set out the results as the proportion of all discordant crypts that are due to partially involved crypts. The Table shows that this proportion, with a median value of $6 \%$ in non-irradiated cases, was considerably increased at $56 \%$ one month after radiation, and fell progressively with time thereafter to reach $16 \%$ at $4-12$ months, $13 \%$ at 13-24 months, and $10 \%$ at $>25$ months. The values at one month and 4-12 months post-radiation are significantly increased compared with non-irradiated cases $(p<$ 0.0001 and $p<0.03$ respectively).

\section{Discussion}

This study shows that after exposure to therapeutic levels of irradiation the human colon shows the same pattern of changes in discordant (mutated) crypts as we have seen in mouse colon after exposure to a chemical carcinogen, but at a very different time scale. It confirms our previous findings that the frequency of mutated crypts identified by mPAS histochemistry in informative cases rises significantly as a consequence of exposure to radiation. ${ }^{10}$ At one month the increase is largely due to crypts that are partially involved by the mutant phenotype; with increasing time after irradiation wholly involved crypts predominate and the frequency of partially involved crypts declines. The frequency of wholly affected crypts appears to reach a plateau after about 12 months, remaining increased for many years thereafter. The overall findings support previous conclusions that wholly affected crypts are persistent and result from fixed mutations of the $\mathrm{O}$-acetyltransferase gene in

Frequencies of discordant (mutated) crypts

\begin{tabular}{|c|c|c|c|c|c|c|c|}
\hline \multirow[b]{2}{*}{$\begin{array}{l}\text { Time since } \\
\text { radiation } \\
\text { (median) }\end{array}$} & \multirow[b]{2}{*}{$\begin{array}{l}\text { Number of } \\
\text { informative } \\
\text { cases }\end{array}$} & \multirow{2}{*}{$\begin{array}{l}\text { Median age } \\
\text { in years at } \\
\text { time of colon } \\
\text { resection } \\
\text { (range) }\end{array}$} & \multirow[b]{2}{*}{$\begin{array}{l}\text { Radiation dose } \\
\text { range } \\
(c G y)\end{array}$} & \multicolumn{3}{|c|}{$\begin{array}{l}\text { Median frequency of discordant crypts } \\
\times 10^{-4} \text { (range) }\end{array}$} & \multirow{2}{*}{$\begin{array}{l}\text { Median \% of } \\
\text { discordant crypts } \\
\text { that were } \\
\text { partially } \\
\text { involved (range) }\end{array}$} \\
\hline & & & & $\begin{array}{l}\text { wholly } \\
\text { involved }\end{array}$ & $\begin{array}{l}\text { partially } \\
\text { involved }\end{array}$ & total & \\
\hline $\begin{array}{l}\text { Non-irradiated } \\
\text { colorectal } \\
\text { cancer cases }\end{array}$ & 53 & $\begin{array}{l}73 \\
(49 \text { to } 94)\end{array}$ & none & $\begin{array}{l}7.5 \ddagger \\
(0 \text { to } 53.4)\end{array}$ & $\begin{array}{l}0.95 \\
(0 \text { to } 4 \cdot 7)\end{array}$ & $\begin{array}{l}7 \cdot 7 \| \\
(0 \cdot 4 \text { to } 53 \cdot 4)\end{array}$ & $\begin{array}{l}61 \\
\left(0 \text { to } 50^{\star}\right)\end{array}$ \\
\hline 1 month $\dagger$ & 7 & $\begin{array}{l}64 \\
\text { ( } 31 \text { to } 73)\end{array}$ & 4000 external & $\begin{array}{l}5 \cdot 3 \\
(0 \cdot 7 \text { to } 17 \cdot 9)\end{array}$ & $\begin{array}{l}6 \cdot 99 \\
(0.7 \text { to } 15 \cdot 6)\end{array}$ & $\begin{array}{l}14 \cdot 0 \\
(1 \cdot 3 \text { to } 26 \cdot 0)\end{array}$ & $\begin{array}{l}56 \text { I } \\
(26.9 \text { to } 61 \cdot 9)\end{array}$ \\
\hline $\begin{array}{l}4 \text { to } 12 \text { months } \\
\text { (11 months) }\end{array}$ & 7 & $\begin{array}{l}60 \\
(52 \text { to } 77)\end{array}$ & $\begin{array}{l}5500 \text { internal to } \\
4800 \text { internal+ } \\
4000 \text { external }\end{array}$ & $\begin{array}{l}24 \cdot 2 \ddagger \\
(9 \cdot 9 \text { to } 39 \cdot 1)\end{array}$ & $\begin{array}{l}6 \cdot 4 \sqrt{(1 \cdot 0} \text { to } 39 \cdot 1)\end{array}$ & $\begin{array}{l}35 \cdot 0 \| \\
(11 \cdot 5 \text { to } 78 \cdot 2)\end{array}$ & $\begin{array}{l}169 \\
(6 \cdot 7 \text { to } 52 \cdot 9)\end{array}$ \\
\hline $\begin{array}{l}13 \text { to } 24 \text { months } \\
\text { (19 months) }\end{array}$ & 5 & $\begin{array}{l}54 \\
(33 \text { to } 70)\end{array}$ & $\begin{array}{l}4000 \text { external to } \\
5500 \text { internal+ } \\
3250 \text { external }\end{array}$ & $\begin{array}{l}28 \cdot 7 \ddagger \\
(4 \cdot 3 \text { to } 114 \cdot 1)\end{array}$ & $\begin{array}{l}3 \cdot 5 \S \\
(0 \cdot 8 \text { to } 17 \cdot 0)\end{array}$ & $\begin{array}{l}29 \cdot 5 \| \\
(5 \cdot 1 \text { to } 131 \cdot 1)\end{array}$ & $\begin{array}{l}13 \\
(2 \cdot 7 \text { to } 16 \cdot 7)\end{array}$ \\
\hline $\begin{array}{l}25 \text { to } 408 \text { months } \\
\text { (53 months) }\end{array}$ & 9 & $\begin{array}{l}65 \\
(46 \text { to } 79)\end{array}$ & $\begin{array}{l}4500 \text { internal to } \\
4800 \text { internalt } \\
2680 \text { external }\end{array}$ & $\begin{array}{l}31 \cdot 7 \ddagger \\
(5 \cdot 8 \text { to } 128 \cdot 3)\end{array}$ & $\begin{array}{l}2 \cdot 15 \\
(0 \text { to } 16 \cdot 1)\end{array}$ & $\begin{array}{l}33 \cdot 8 \| \\
(6 \cdot 7 \text { to } 144 \cdot 4)\end{array}$ & $\begin{array}{l}10 \\
(0 \text { to } 45 \cdot 5)\end{array}$ \\
\hline
\end{tabular}

* excluding one case with only a single partially involved crypt.

Statistically significant differences (Mann-Whitney $U$ ): $\neq$ non-irradiated $v$ 4-12 months, 13-24 months and $>25$ months: $p<0 \cdot 03$; Statistically significant differences (Mann-Whitney $U$ ): $¥$ non-irradiated $v$-12 months, $13-24$ months and $>25$ months: $p<0 \cdot 03$;
(non-irradiated $v 1$ month, 4-12 months, $13-24$ months and $>25$ months: $p<0 \cdot 04$; |non-irradiated $v$ 4-12 months, $13-24$ months non-irradiated $v 1$ month, 4-12 months, $13-24$ months and $>25$ months: $\mathrm{p}<0 \cdot 04 ;$
and $>25$ months: $\mathrm{p}<0 \cdot 03$; 9 non-irradiated $v 1$ month and 4-12 months: $\mathrm{p}<0 \cdot 03$. 
long lived stem cells while partially affected crypts are transient, resulting either from relatively recent stem cell mutations whose progeny have not yet colonised the whole crypt, or post-stem cell mutations in the proliferative compartment of the crypt. ${ }^{10}$

A particular point of interest is the decline with time after radiation in the proportion of all discordant crypts that is composed of partially involved crypts (Table), a ratio that animal studies suggest is independent of the tissue dose. ${ }^{45}$ In a previous study of mutation in mouse colon using a different marker (the $\mathrm{X}$-linked enzyme G6PD) we also found a fall with time in this proportion after a single dose of mutagen, either ethylnitrosourea or dimethylhydrazine. ${ }^{4}$ This change in the relative proportions of wholly involved crypts and partially involved crypts could be explained on the basis that there is a single crypt stem cell with a long cycle time, partially involved crypts resulting from mutations in relatively long lived non-stem cells or in stem cells repopulating the crypts. A more plausible explanation is that the crypts are maintained by a stem cell niche in which there are two or more stem cells per crypt and the loss of cells from the niche after cell division is at least partly random. ${ }^{4}$ Mutation in one stem cell will then maintain a mixed phenotype crypt until either the mutated stem cell is lost or the mutated stem cell line replaces the non-mutated stem cells. In the mouse colon, after a single mutagen dose, the proportion of all discordant crypts formed by mixed phenotype crypts returns to normal in about four weeks. ${ }^{45}$ In the mouse small intestine the time is between $12^{5}$ and $21^{26}$ weeks, depending on which experimental model is used. We have termed this the clonal stabilisation time - the time taken for phenotype stability to be achieved within clonal units (in this case colonic crypts) after a single exposure to a mutagen. Our current findings suggest that in the human colon it is of the order of 12 months. It is unlikely to be much less than one year because the median percentage of partially involved crypts is significantly higher than the non-irradiated cases at both one month and 4-12 months post-irradiation and remains higher at 13-24 months after irradiation (though the latter difference does not reach statistical significance). Moreover the time since irradiation is not randomly distributed in the 4-12 month group, but is skewed towards the upper limit of the time range with a median of 11 months.

The very long clonal stabilisation time in the human of about 12 months compared with the four weeks in mouse colon could result from a number of factors including a larger number of stem cells in the crypt stem cell niche in humans or a longer stem cell cycle time. It could also be influenced by an alteration affecting the probability that the loss of a cell from the niche occurs at random. This raises the possibility that a mutation affecting a growth control gene or one involved in cell signalling could influence this probability, giving a mechanism that could reduce the chance of potentially carcinogenic mutations persisting in stem cells. Whether this mechanism exists remains to be proved, but the kinetics of the crypt stem cell are clearly relevant to the process of colorectal neoplasia.

Several other issues require consideration, including the persistence of an increased frequency of partial mutated crypts over many years, the unusually high proportion of the group of irradiated patients who were apparently heterozygotes for O-acetyltransferase activity, and mechanisms other than the crypt niche hypothesis, which could explain the change in the relative proportion of partially involved crypts with time.

The crypt niche model for three stem cells predicts an asymptotic fall in the number and proportion of partially involved crypts with time after mutagen exposure. ${ }^{4}$ If a niche contains a greater number of stem cells, sufficient for one to be surrounded by other stem cells, the shape of the niche and the position of the mutated stem cell within it will influence the time taken for the crypt to reach phenotypic stability. The long continued increase in the absolute frequency of partially affected crypts is therefore explicable on a stem cell niche model. We have considered the possibility that partially involved crypts continue to be generated because of a rise in mutation rate that persists for years after exposure to high dose radiation - a number of in vitro mutagenicity studies, recently reviewed by Kronenberg, ${ }^{13}$ have suggested that $x$ radiation not only produces somatic mutation from direct DNA damage to radiated cells but also induces a persistent destabilisation of the genome predisposing to chromosomal instability and a permanent increased susceptibility to mutation in the surviving progeny. However, because of the similarity of the total mutated crypt frequencies at 4-12, 13-24, and $>25$ months after irradiation it is unlikely that continuing new stem cell mutations resulting from such a late irradiation effect make more than a small contribution to the raised partially involved crypt count.

The frequency of mutated crypts cannot unfortunately be related on an individual case basis to the tissue exposure to radiation in this study. The uncertainty is due to the rapid fall in dose with distance from the intracavitary source used in many cases, and the lack of knowledge of the precise anatomical location of the portion of colon from which the blocks studied were derived. It is therefore probable that in some or all of the three irradiated cases with the lowest level of discordant crypts $\left(<9 \times 10^{-4}\right)$ the colonic mucosa assessed was outside the radiation field. An alternative explanation that must be considered is that some of these cases were homozygous rather than heterozygous for a high level of $\mathrm{O}$-acetyl transferase activity. Of the 30 unselected cases, four showed diffuse mPASpositivity, consistent with homozygosity for low $\mathrm{O}$-acetyltransferase activity. This proportion is similar to that found in previous studies. ${ }^{8}$ However, in this study the proportion of cases with discordant crypts was higher than expected both from previous studies, and from application of the Hardy-Weinberg law (although the 
difference is not statistically significant by the $\chi^{2}$ test, $p>0 \cdot 1$ ). This may result from chance, or it could be the consequence of mutation in homozygotes. The highest total mutation rate observed in a single case was $144.4 \times 10^{-4}$. The mutation frequency in homozygotes where two hits are required to produce loss of function, is predicted to be the square of that in heterozygotes, where one hit only is needed. A mutagen leading to a discordant crypt frequency of $144.4 \times 10^{-4}$ in a heterozygote would therefore be expected to give a frequency of $2 \cdot 1 \times 10^{-4}$ in a homozygote. This is a detectable level, and would be higher if, as is probably the case, the mutations were clustered in one part of the colon because of a steep gradient in tissue dose. The relatively high proportion of apparent heterozygotes may well result from chance, but we cannot exclude the possibility that some of the cases with a low count are due to mutations in homozygotes exposed to very high levels of radiation.

It has recently been suggested that crypts preparing to undergo fission increase their stem cell number, that these crypts are particularly liable to stem cell mutation, and that the conversion of a partially involved to a wholly involved crypt takes place at the time of crypt fission. ${ }^{5}$ In this model crypts would be maintained by more than one stem cell, but the control of asymmetry could be intrinsic to the stem cell. Crypt fission clearly is a mechanism that could contribute to the conversion of a partially mutated crypt to a wholly mutated crypt and a phenotypically normal crypt, although if more than two stem cells are present per crypt several rounds of crypt fission would probably be required to give a uniform phenotype. We have rarely observed a wholly involved crypt adjacent to a partially involved crypt, which could have arisen by fission of a partially involved crypt with a minimum of three stem cells at the time of crypt fission. Crypt fission rates decline with age ${ }^{5}$ so that if this was an important factor in the susceptibility to mutation and in clearance of partially involved crypts, the stem cell mutation rate would be expected to fall with age and the clearance rate to lengthen. In fact we find experimentally that 30 days after a single dose of mutagen the colonic somatic mutation frequency induced in 27 month old mice is higher than in 3 month old animals ${ }^{14}$ but the ratio of wholly to partially involved crypts is very similar in both age groups (unpublished findings). For this and other reasons we think it unlikely that crypt fission plays more than a minor part in the clearance of partially involved crypts.
We regard the clonal stabilisation time as the time taken for virtually all genetically altered cells either to be lost from a clone or to replace all the cells of a clone. In the colon we regard the crypt as the clonal unit, even though we consider it likely to be maintained by a stem cell niche, and we have shown that the crypt stabilisation time in humans is about one year. Knowledge of the mechanisms that control this time and lead to species and tissue differences is relevant to theories of carcinogenesis. Knowledge of the time itself is relevant to gene therapy, ${ }^{15}$ as it is the interval that must pass before permanent levels of expression of introduced genes can be guaranteed.

We wish to thank the following for providing histopathological material and clinical information: C G B Simpson and C S materl (And clinical information. C G B Simpson an Maughan (Cardiff), J Piris (Edinburgh), F M Elliot (Fife), R D Jones (Glasgow), J Hallgrimsson (Iceland), N Slevin (Manchester), M P Greeff (Natal), S Howel (Neath). We also thank Dr C E Fuller for data previously published and Dr Fraser Campbell for statistical help.

Part of this study was presented at the 167th Meeting of the Pathological Society of Great Britain and Ireland, Edinburgh June 1993 and published as an abstract in $\mathcal{F}$ Pathol 1993; 170: $340 \mathrm{~A}$.

1 Griffiths DFR, Davies SJ, Williams D, Williams GT, Williams ED. Demonstration of somatic mutation and colonic crypt clonality by $\mathrm{X}$-linked enzyme histochemistry. Nature 1988; 333: 461-3.

2 Winton DJ, Blount MA, Ponder BAJ. A clonal marker induced by mutation in mouse intestinal epithelium. Nature 1988; 333: 463-6.

3 Potten CS, Loeffler M. Stem cells: attributes, cycles, spirals, pitfalls and uncertainties. Lessons for and from the crypt. pitfalls and uncertainties. Lessons

4 Williams ED, Lowes AP, Williams D, Williams GT. A stem cell niche theory of intestinal crypt maintenance based on a study of somatic mutation in colonic mucosa. $A m \mathcal{F}$ Pathol 1992; 141: 773-6.

5 Park HS, Goodlad RA, Wright NA. Crypt fission in the small intestine and colon: a mechanism for the emergence of G6PD locus-mutated crypts after treatment with mutagens. Am $\mathcal{f}$ Pathol 1995; 147: 1416-27.

6 Winton DJ, Ponder BAJ. Stem-cell organisation in mouse small intestine. Proc $R$ Soc Lond B 1990; 241: 13-8.

7 Loeffler M, Birke A, Winton D, Potten C. Somatic mutation, monoclonality and stochastic models of stem mutation, monoclonality and stochastic models of stem 160: 471-91.

8 Campbell F, Appleton MAC, Fuller CE, Greeff MP, Hallgrimsson J, Katoh R, et al. Racial variation in the O-acetylation phenotype of human colonic mucosa. $f$ Pathol 1994; 174: 169-74.

9 Fuller CE, Davies RP, Williams GT, Williams ED. Crypt restricted heterogeneity of goblet cell mucus glycoprotein in histologically normal colonic mucosa: a potential marker of somatic mutation. Br $\mathcal{f}$ Cancer 1990; 61: $382-4$.

10 Campbell F, Fuller CE, Williams GT, Williams ED. Human colonic stem cell mutation frequency with and without radiation. $\mathcal{f}$ Pathol 1994; 174: 175-82.

11 Veh RW, Meessen D, Kuntz D, May B. A new method for histochemical demonstration of side chain substituted histochemical demonstration of side chain substituted sialic acids. In: Malt RA, Williamson RCN, eds.
carcinogenesis. Lancaster: MTP, 1982: 355-65.

12 Campbell F, Williams GT, Williams ED. Colonic $\mathrm{O}$-acetylation phenotype and somatic mutation. $\mathcal{f}$ Pathol 1995; 176: 322-3.

13 Kronenberg A. Radiation-induced genomic instability. Int $f$ Radiat Biol 1994; 66: 603-9.

14 Lowes A, Williams D, Williams GT, Williams ED. Stem cell somatic mutation and ageing. 7 Pathol $1992 ; 167$ : $135 \mathrm{~A}$

15 Pandha HS, Lemoine NR. Gene therapy in gastroenterology. Gut 1996; 38: 161-5. 